\title{
Postharvest Stimulation of Skin Color in Royal Gala Apple
}

\author{
Yi hu Dong, Deepali Mitra, and Arend Kootstra ${ }^{1}$ \\ Horticulture and Food Research Institute of New Zealand Ltd, Private Bag 92169, Auckland, \\ New Zealand \\ Carolyn Lister and Jane Lancaster \\ New Zealand Institute for Crop and Food Research Ltd., Private Bag 4704, Christchurch, New Zealand \\ Additional index words. Malus domestics, ultraviolet light, anthocyanin, PAL, CHI, gene expression
}

\begin{abstract}
The red color of Royal Gala apple (Malus domestics Borkh.) skin increased in intensity following irradiation with ultraviolet (UV) and white light. The enhanced red apple color was due to an increase in anthocyanin concentration and the increase was dose dependent. High-performance liquid chromatography analysis showed that the composition of flavonoids in UV treated and natural red colored apple skins was similar. The red apple skin color further increased after storage at $4 \mathrm{C}$ in the dark. During the course of irradiation the enzymatic activities of phenylalanine ammonia lyase (PAL) and chalcone isomerase (CHI) increased 10-to 20-fold. Northern analysis showed an increase in PAL transcripts during the irradiation treatment, suggesting that the increase in PAL enzymatic activity was due to de novo synthesis of the enzyme in apple skin cells.
\end{abstract}

The range of red and purple colors in many flowers and fruits is primarily a consequence of anthocyanin molecules (Dooner, 1983; Forkmann, 1991; Saure, 1990; Van der Meer et al. , 1993). The biosynthesis of anthocyanins has been extensively studied in several plant systems. These molecules, which belong to the general class of plant secondary metabolizes, are called flavonoids. These can be synthesized in response to many environmental factors such as light, cold stress, pathogen attack, mechanical damage, and developmental-genetic factors (Kuhn et al., 1984; Lamb et al., 1989; Ohl et al., 1989).

Apple skin color is a significant factor in the economics of the fresh apple fruit industry, since it plays an important role in consumer appeal. Although the intensity and quality of the redskin color is directly related to the anthocyanin concentration and molecular substitution, the final apple skin color as we perceive it is thought to be determined by the interaction of anthocyanin molecules with other compounds (Harborne, 1988; Forkmann, 199 1). Thus, the subtle changes in red color intensity or hues seen in many apple cultivars may be a consequence of co-pigmentation (Mazza and Brouillard, 1990) as well as local hydrogen ion concentration in the individual intracellular vacuoles (Asen et al., 197 1; de Vlaming et al., 1984), where the anthocyanin molecules are concentrated (Hrazdina and Wagner, 1985). Recent results (Lancaster et al., 1994) have shown that the quantities of chlorophyll and carotenoid pigments present in the apple skin are also important factors in determining the final red color. Clearly there are many complex interactions that will dictate the final color of apple skin as we perceive it.

The development of postharvest treatment regimes that will modulate and generate a desirable apple skin color, without affecting other characteristics of the apple cultivar, are important considerations in capturing and developing competitive markets. Although genetic engineering provides an exciting opportunity that

Received for publication 18 Apr. 1994. Accepted for publication 8 Aug. 1994. The cost of publishing this paper was defrayed in part by the payment of page charges. Under postal regulations, this paper therefore must be hereby marked advertisement solely to indicate this fact.

'To whom reprint requests should be addressed at BioText International, P.O. Box 32103, Devonport, Auckland, New Zealand. will eventually influence fruit color, the time frame of 10 to 15 years to deliver a commercial transgenic pipfruit crop and the limited flexibility to accommodate short-term market trends indicate that nonchemical and nontoxic manipulation of fruit color at the postharvest level would be a highly desirable intermediate goal. In this framework we are studying the biosynthesis of anthocyanin in commercial apple cultivars.

The biosynthesis of anthocyanins in apple skin, as in other plant tissues, starts with the conversion of phenylalanine to cinnamic acid by the enzyme phenylalanine ammonia lyase (Lancaster, 1992; Van der Meer et al., 1993). In two subsequent reactions coumaroyl-CoA is produced. Chalcone synthase (CHS), the first enzyme in the flavonoid-anthocyanin biosynthetic pathway, then catalyses the condensation of coumaroyl-CoA with three molecules of malonyl CoA to produce the yellow colored tetrahydroxy chalcone, which is subsequently isomerized by chalcone isomerase to naringenin. Naringenin, which is colorless, is the first of the flavonoid molecules in the flavonoid pathway. Subsequent enzymatic modification of the flavonoid structure involves hydroxylation, methylation, acylation, glycosylation, and reduction to produce the $>3500$ different flavonoid derivatives including the unstable leucoanthocyanidins and anthocyanidins (Harborne, 1988). The anthocyanidins are stabilized by glycosylation, a reaction catalysed by UDPG flavonoid: 3-O-glucosyltransferase (3GT). The three groups of anthocyanins present in plants are 1) the cyanidins, 2) the pelargonidins, and 3) the delphinidins. The latter group of compounds, the delphinidins, are largely absent in the family Rosaceae, to which apple (Malus) belongs.

In a variety of plant species the biosynthesis of anthocyanins is regulated in a developmental and tissue specific manner (Coe et al., 1988; Tonelli et al., 1991; Jackson et al., 1992; Kubasek et al., 1992). In particular, the $R$ and $C l$ genes appear to control the coordinate expression of structural genes involved in the biosynthesis of anthocyanins (Ludwig et al., 1989; Roth et al., 1991; Consonni et al., 1993; van der Meer et al., 1993). The $R$ and $C l$ genes belong to a family of genes that code for transcription factors. The protein structures deduced from the $R$ and $C l$ DNA sequences bear a striking resemblance to the proto-oncogenes myc and $m y b$, respectively, in that the DNA binding domain and the protein-protein interactive domains of these transcription factors 
Table 1. Royal Gala apple skin color development during storage at different time points. Apples were irradiated with UV and white light $(\mathrm{UV}+\mathrm{W}$ ) or white light only (W) for 1,2 , or 3 days. Values are means \pm SE of six apples before (B), after (A), and after 15 days (D 15) or 70 days (D70) of storage in the dark at 4C. Unirradiated control apples (Dark) were measured at day 0 (D0), day 15 (D15), and day 70 (D70) of storage in the dark at $4 \mathrm{C}$.

\begin{tabular}{lccc}
\hline \hline & \multicolumn{3}{c}{ Irradiation (days) } \\
& 1 & 2 & 3 \\
\cline { 2 - 4 } Treatment & \multicolumn{3}{c}{ Color a* values } \\
\hline UV+W & & \\
B & $-14.7 \pm 1.5$ & $-11.7 \pm 1.1$ & $-12.2 \pm 1.4$ \\
A & $5.1 \pm 3.2$ & $11.6 \pm 3.4$ & $26.4 \pm 2.8$ \\
D15 & $24.2 \pm 3.7$ & $36.0 \pm 4.2$ & $36.9 \pm 2.1$ \\
D70 & $25.4 \pm 2.7$ & $35.7 \pm 0.6$ & $36.5 \pm 0.4$ \\
W & & & \\
B & $-15.2 \pm 1.1$ & $12.9 \pm 1.1$ & $-13.3 \pm 2.3$ \\
A & $-13.3 \pm 2.3$ & $-6.1 \pm 4.9$ & $-4.4 \pm 4.3$ \\
D15 & $-8.3 \pm 2.7$ & $0.6 \pm 1.8$ & $7.7 \pm 13.4$ \\
D70 & $-7.7 \pm 1.1$ & $0.7 \pm 3.1$ & $8.5 \pm 0.1$ \\
Dark & & & \\
D0 & & $-14.7 \pm 0.8$ & \\
D15 & & $-14.2 \pm 1.7$ & \\
D70 & & $-13.6 \pm 0.2$ & \\
\hline
\end{tabular}
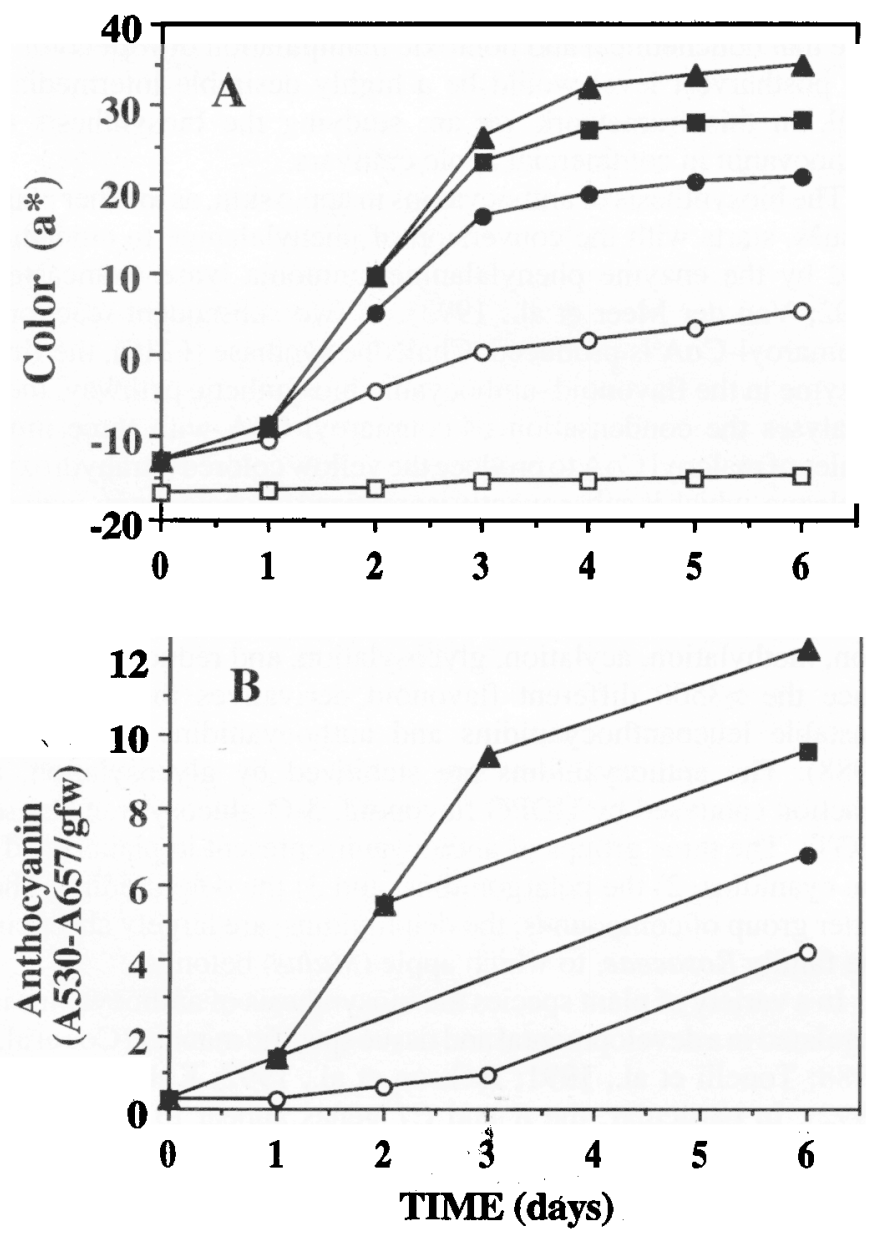

Fig. 1. Accumulation of red pigment and total anthocyanins in Royal Gala apple skin after irradiation under constant white light conditions with UV light for 0 $(\mathrm{O}), 1(\bullet), 2(\boldsymbol{\square})$, and $3(\boldsymbol{\Delta})$ days. Control apples( $\square)$ were left in the dark under identical conditions. Data points for color $\left(\mathrm{a}^{*}\right)$ values and anthocyanin concentrations represent the mean of six and three independent samples respectively. were shown to be highly conserved between animals and plants (Goodrich et al., 1992; Jackson et al., 1992; Avilla et al., 1993; Consomi etal., 1993).

Our research has been directed toward understanding the mechanism that controls the degree of pigmentation in several New Zealand apple cultivars. The results described in this paper are part of our long-term research goals and strategies to develop new technology for improving apple color and to understand the mechanism of induction and expression of specific pigmentation genes in apple skin.

\section{Materials and Methods}

Plant material. Green, preclimacteric Royal Gala apples were harvested from the shaded centres of the trees and stored at $4 \mathrm{C}$ in the dark for a minimum of 3 days and a maximum of 5 weeks. They were subjected to ultraviolet (UV) irradiation using a broad wavelength UV fluorescent light source with an average fluency rate of $150 \mu \mathrm{W} \cdot \mathrm{cm}^{-2}$, measured at $310 \mathrm{~nm}$, at a distance of $58 \mathrm{~cm}$ with a radiometer (UVX; UVP, San Gabriel, Calif.) and to white light from fluorescent lamps that had a fluency rate of $400 \mu \mathrm{E} / \mathrm{m}^{2}$ per sec. All irradiation experiments were carried out at $14 \pm 0.5 \mathrm{C}$ and the UV and white light sources were $58 \mathrm{~cm}$ and $2.6 \mathrm{~m}$ from the apples respectively. Apples were kept on a rotating platform during the entire irradiation period.

Color and flavonoid measurements. To determine the development of apple skin color in response to irradiation, apple skin color was measured with a Minolta Chromameter II, in the CIELAB (L*, $\mathrm{a}^{*}, \mathrm{~b}^{*}$ ) color space abbreviation (McGuire, 1992; Voss, 1992). A good correlation was obtained between the $\mathrm{a}^{*}$ values and the degree of red pigmentation in Royal Gala apple skin. Total anthocyanins were extracted from apple skin overnight with $1 \%$ HC1-methanol, and the absorbance of extracts was measured at $530 \mathrm{~nm}$ and $657 \mathrm{~nm}$ as described by Kubasek et al. (1992) from three independent samples. The difference between $A_{530}$ and $A_{657}$ was used to determine the concentration of total anthocyanin and

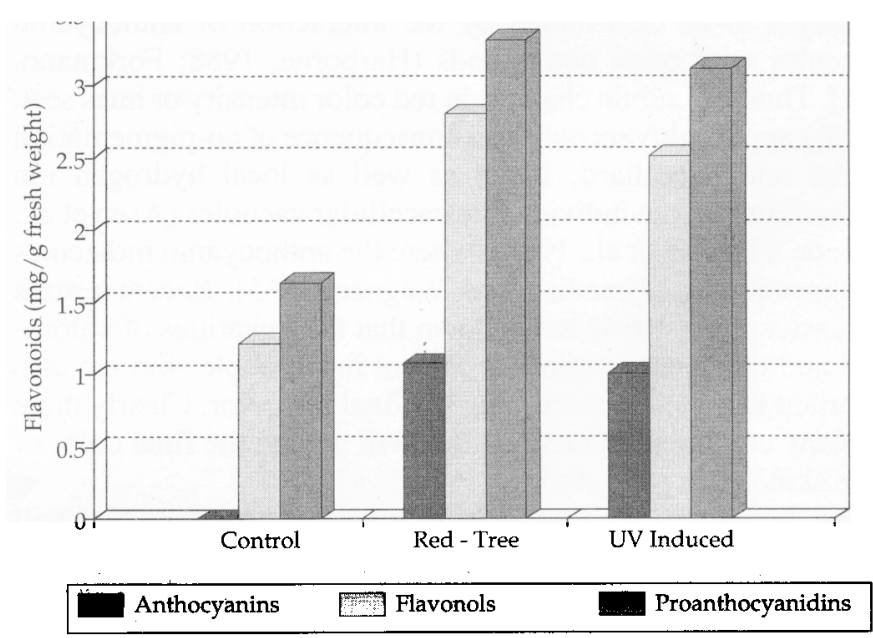

Fig. 2. Flavonoid quantification UV-induced and natural red apple skin. Flavonoids were extracted from UV irradiated and natural (red-tree) apple skin and quantified by HPLC. The main anthocyanin was cyanidin-3-galactoside. The flavonols consisted of a number of quercetin glycosides. The proanthocyanidins were predominantly catechin, epicatechin, and procyunidin B2 and B5. Data is expressed as the mean of six samples. There were no significant differences in the relative composition of these individual compounds in the UV irradiated and natural colored Royal Gala apple skin samples. Control apples were unirradiated preclimacteric Royal Gala apples. 


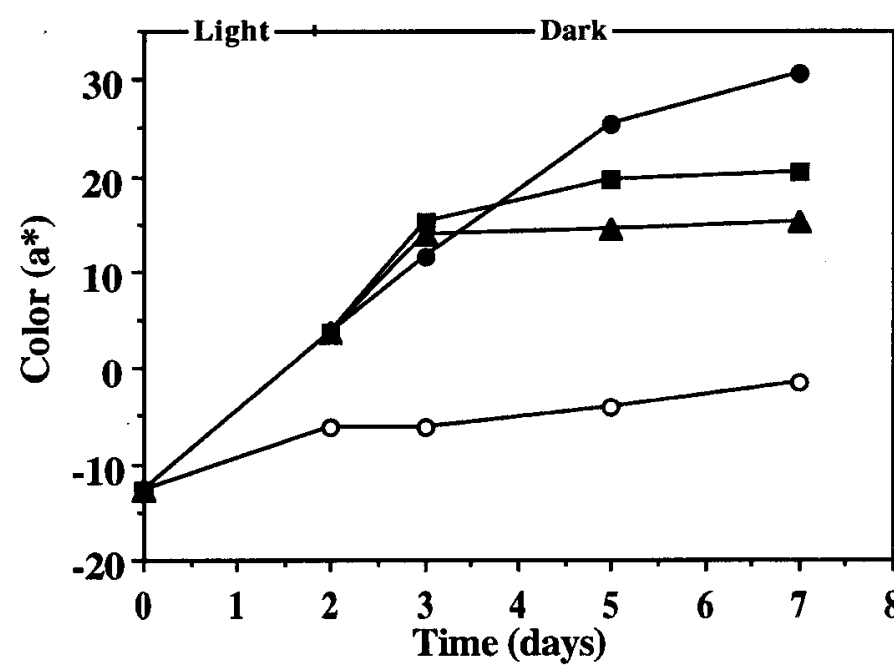

Fig. 3. Effect of storage temperature on apple color development. Royal Gala apples were irradiated with UV and white light for 2 days at $14 \mathrm{C}$ and stored in the dark for an additional 5 days at $4 \mathrm{C}(\boldsymbol{\bullet}), 14 \mathrm{C}(\mathbf{\square})$, and $25 \mathrm{C}(\boldsymbol{\Delta})$. Control apples ( $\square$ ) were exposed to white light only for 2 days and were stored in the dark at $14 \mathrm{C}$. Each data point is the mean of six samples.

eliminate the contribution made by chlorophyll and its degradation products (Rabino and Mancinelli, 1986; Feinbaum and Ausubel, 1988).

To correlate the red color development with anthocyanin accumulation in apple skin, flavonols, anthocyanins, and proanthocyanins were extracted from six independent samples and quantified by high-performance liquid chromatography (HPLC) analysis as described by Lister et al. (1993). The HPLC eluate was monitored at $350 \mathrm{~nm}$ for flavonols and at $530 \mathrm{~nm}$ for anthocyanins. Proanthocyanins were monitored at $280 \mathrm{~nm}$ and phenolic acids at $313 \mathrm{~nm}$. Standards used to quantify the HPLC data were cyanidin-3-galactoside, quercetin-3-galactoside, quercetin-3-glucose, quercetin-3-rhamnose, and quercetin-3-xylose (Plantech, Reading, U.K.). (+)-Catechin, phloridzin and quercetin-3 -rhamnosylglucoside (rutin) were purchased from Sigma Chemical Co., St. Louis, and quercetin-3-arabinose was obtained from Extrasynthese, Lyon, France. (-)-Epicatechin polymer, (+)-gallocatechin, procyanidin B2, and procyanidin B5 were donated by L. Porter (Industrial Research Ltd., Lower Hutt, New Zealand).

Enzyme extraction and assay. To study the activities of enzymes in the phenylpropanoid and flavonoid pathways, phenylalanine ammonia lyase (PAL) was extracted and assayed essentially as described by Faragher and Chalmers (1977). Apple skin (0.5 to $1.0 \mathrm{~g}$ ) was ground in a mortar and pestle with $10 \mathrm{ml}$ of $0.1 \mathrm{M}$ borate buffer ( $\mathrm{pH}$ 8.8) containing 2-mercaptoethanol (20 mM) and $0.4 \mathrm{~g}$ Polyclar AT per gram fresh weight (gfw) of apple skin. The extract was centrifuged at $20,000 \times \mathrm{g}$ for $30 \mathrm{~min}$ at $4 \mathrm{C}$. Proteins were precipitated from the supernatant with ammonium sulfate $(70 \%$ saturation) and pelleted by centrifuging for $15 \mathrm{~min}$ as described above. The resulting precipitate was gently resuspended in $5 \mathrm{ml}$ of borate buffer and used as the enzyme solution. The assay mixture (3 ml) consisted of $0.1 \mathrm{M}$ borate buffer ( $\mathrm{pH} 8.8$ ), $20 \mu \mathrm{M} \mathrm{L}$ phenylalanine, and enzyme solution containing 50 to $100 \mu \mathrm{g}$ protein. Absorbance measurements were made with a Hitachi U2000 spectrophotometer. All reactions were equilibrated for 10 min at $40 \mathrm{C}$. The change in $\mathrm{A}_{290}$ over $60 \mathrm{~min}$ was used to determine PAL activity. Linearity of kinetics was established in separate experiments. PAL activity was expressed as pkat/pg protein. Protein concentration was determined by the method of Bradford (1976) using bovine serum albumin as a standard.

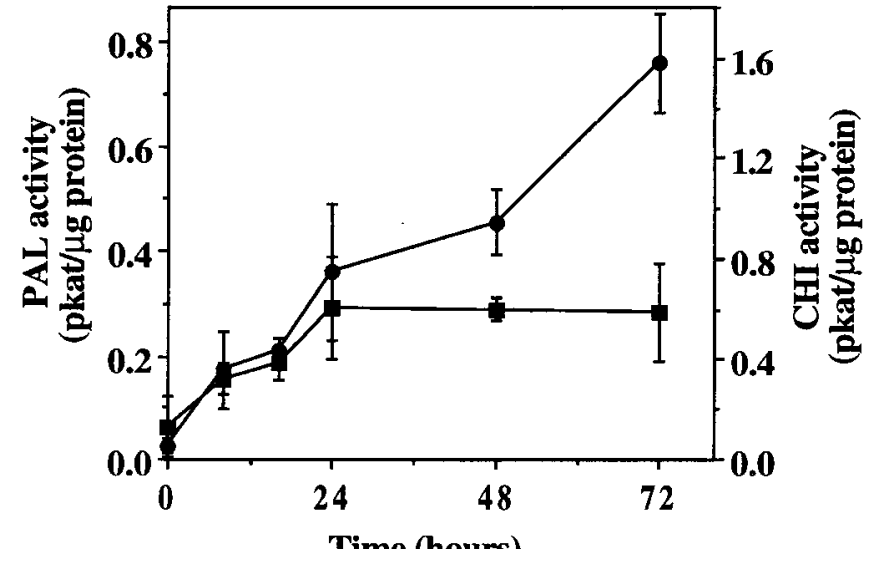

Fig. 4. Phenylalanine ammonia lyase and chalcone isomerase activities in apple skin following irradiation with UV and white light irradiation for; $0,8,16,24$, 48, and $72 \mathrm{~h}$. The enzymatic activities for PAL ( $)$ and CHI ( $\mathbf{0}$ ) are expressed in pkat/ $\mu \mathrm{g}$ of protein. Every point is the average of six samples. Vertical bars represent SE of the mean.

Chalcone isomerase (CHI) was isolated as described by Mol et al. (1985). Apple skin (1.0 g) 'was pulverised in a mortar and pestle containing $1 \mathrm{~g}$ of Dowex $1-\mathrm{X} 4$, acid-purified sand $(0.5$ to $1.0 \mathrm{~g})$, and $5 \mathrm{ml}$ of $0.1 \mathrm{M}$ sodium phosphate $\mathrm{pH} 8.0$ containing $1.4 \mathrm{~mm} 2-$ mercaptoethanol. The homogenate was centrifuged for $15 \mathrm{~min}$ $(12,500 \times g)$ in a microfuge and the supernatant was used as the CHI enzyme preparation. The CHI activity was assayed according to Weely et al. (1983). The reaction mixture $(1 \mathrm{ml})$ contained $0.1 \mathrm{M}$ sodium phosphate ( $\mathrm{pH} 8.0$ ), $10 \mathrm{mM} \mathrm{KCN}$ (to inhibit peroxidase degradation of the tetrahydroxy-chalcone), $10 \mathrm{~mm}$ ethylene glycol monomethyl ether, and $0.6 \mathrm{~mm}$ 2',4,4',6'-tetrahydroxy-chalcone. Tetrahydroxy-chalcone was prepared as described by Mustafa and Wong (1967). The reaction was started by the addition of CHI extract, containing 5 to $10 \mu \mathrm{g}$ of protein. The rate of enzymatic and nonenzymatic cyclization of tetrahydroxy-chalcone was determined as a change in $\mathrm{A}_{385}$. The enzymatic conversion of tetrahydroxy-chalcone was measured for 3 rein, during which the reaction showed linear kinetics. All enzyme activity data were corrected for nonenzymatic isomerization and the results are expressed as pkat/ $\mu \mathrm{g}$ protein.

RNA isolation and Northern analysis. Total RNA was extracted from Royal Gala apple skin using a high salt-ethanol precipitation step and $\mathrm{CsC} 1$ ultracentrifugation as described by Mitra and Kootstra (1993). For Northern analysis, the RNA was electrophoresed in a formaldehyde agarose gel (Sambrook et al., 1989) and the RNA was alkaline transfered to a Hybond-N+ membrane. The membrane was probed with a ${ }^{32} \mathrm{P}$ labeled probe representing either the apple PAL gene or the ribosomal gene sequence. Probes were ${ }^{32} \mathrm{P}$ labeled using a random primer protocol (GibcoBRL, Bethesda, Md.).

\section{Results and Discussion}

Induction of appleskin color. Green, preclimacteric Royal Gala apples were subjected to continuous irradiation with UV and white light at $14 \mathrm{C}$ for up to 3 days, and the apple color was determined chromametrically during a 6-day period. Figure 1a shows that control apples, which were left in the dark under identical conditions, did not change color significantly during the 6-day period. Exposure of preclimacteric Royal Gala apples to white light alone produced a striped redpattern that was characteristic of normal tree ripened fruit. Addition of UV light with a fluency of $150 \mu \mathrm{W} \cdot \mathrm{cm}^{-2}$ produced a marked increase in the development of red apple skin 


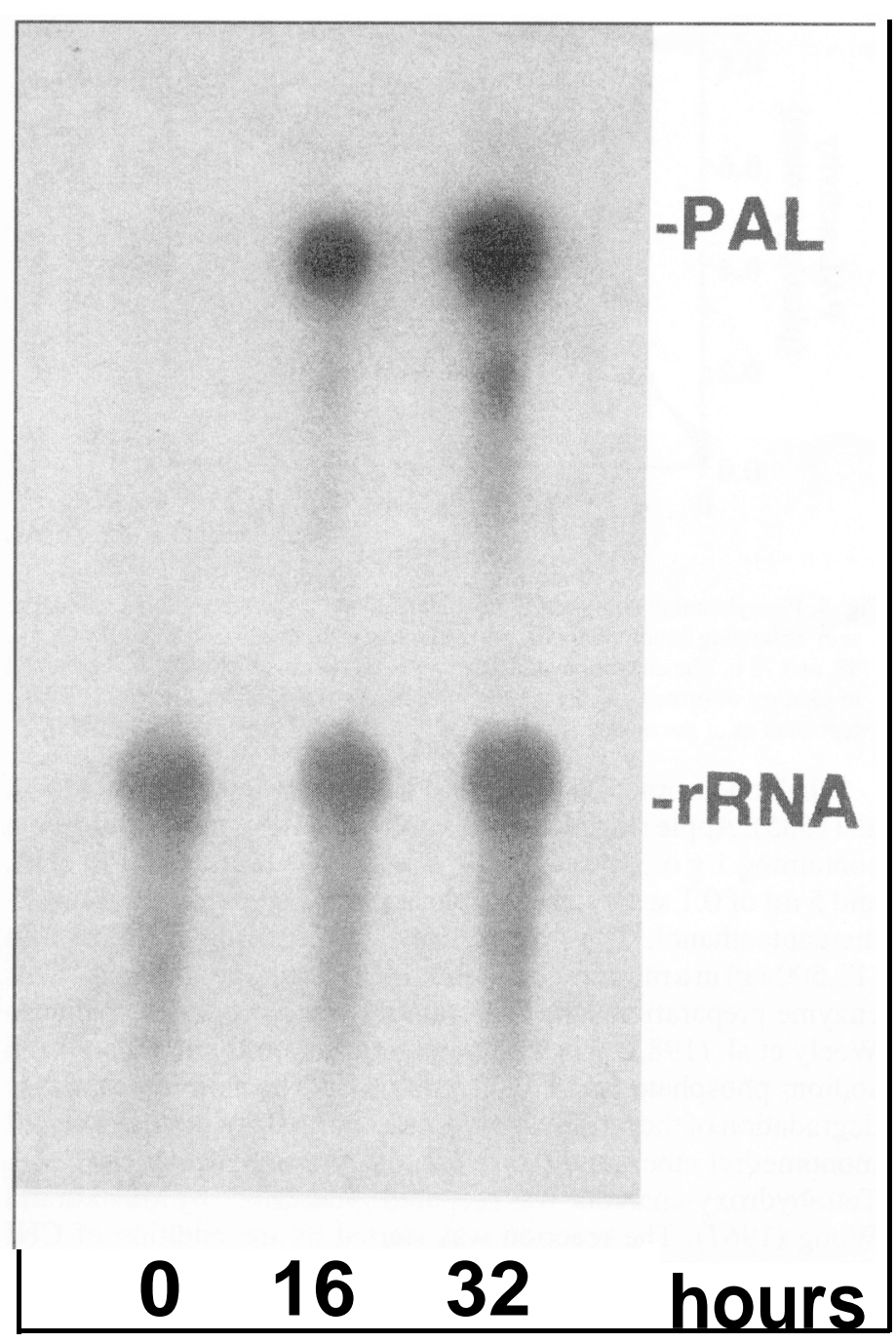

Fig. 5. Northern analysis of PAL gene expression in Royal Gala apple skin. Total RNA was isolated from Royal Gala apple skin following UV plus white light irradiation for 0,16 , and $32 \mathrm{~h}$. Total apple skin RNA was electrophoresed and transfered to a Hybond-N+ membrane, and probed first for PAL mRNA, stripped and reprobed for rRNA under standard conditions. The membrane was washed at high stringency and autoradiography was carried out for 3 days at $-70 \mathrm{C}$ with intensifying screens.

color. The increase in red apple skin color took place after an initial lag period of $\approx 24 \mathrm{~h}$ as has been observed in other apple cultivars (Arakawa, 1988; Faragher and Chalmers, 1977). Further exposure to white light, after the 3-day UV light treatment resulted in a smaller but still noticeable increase in apple skin color. These results suggest that under the experimental conditions described, exposure to UV light and white light will significantly enhance the development of Royal Gala apple skin color by increasing the rate of anthocyanin biosynthesis.

To determine whether the chromametric $a^{*}$ values correlated with the anthocyanin concentrations, Royal Gala apple skin was isolated at different times after UV and white light irradiation and the anthocyanin concentration was determined from three independent analyses using $\mathrm{A}_{530}$ minus $\mathrm{A}_{657}$, The data (Fig. $1 \mathrm{~b}$ ) show that total anthocyanins isolated from apple skin increased as a function of irradiation treatment. The relative changes in apple skin color $\left(\mathrm{a}^{*}\right.$ values $)$ and the total extracted anthocyanin $\left(\mathrm{A}_{530}\right.$ minus $\mathrm{A}_{657}$ ) during the irradiation treatment were similar. Consequently $\mathrm{m}$ these experiments, the $\mathrm{a}^{*}$ values adequately reflect the relative concentration of anthocyanins accumulated in Royal Gala apple skin tissue. However if an accurate description of color is required, consideration and manipulation of the $L^{*} a^{*} b^{*}$ values as described by McGuire (1992) and Voss (1992) will be necessary. Using the $a^{*}$ values (Fig. 1a) or total anthocyanin concentration (Fig. lb), we observed a 1.6- and 1.8-fold increase respectively in red pigmentation in Royal Gala apple skirt tissue following exposure to UV light for 1 and 3 days. As shown by Arakawa et al. (1985) and Faragher and Chalmers (1977) with different apple cultivars, UV plus white light had a synergistic effect in stimulating anthocyanin biosynthesis in Royal Gala.

Comparison of metabolizes in UV light induced and natural red pigmentation. Relative distribution and concentrations of anthocyanins, flavonols, and pro-anthocyanins were very similar in the UV-treated and naturally colored Royal Gala apple skin (Fig. 2). Thus, the increase in pigmentation caused by UV light did not involve a major change in the nature of the normal pigments. Compared to the levels of metabolizes in the nonirradiated Royal Gala apples (Fig. 2), UV + white light irradiation stimulated the entire flavonoid pathway, since the anthocyanins, flavonols, and proanthocyanins were all increased.

Effect of temperature on anthocyanin biosynthesis following $U V$ irradiation. To determine the effect of temperature on apple skin color development after UV light exposure, Royal Gala apples were treated with UV and white light for 2 days and then stored in the dark at 4,14 , or $25 \mathrm{C}$. Color development was measured during a 7-day period. As shown in Fig. 3, after 2 days of UV and white light exposure at 14C anthocyanin accumulation in the intact apple skin increased daily during storage in the dark only for apples stored at 4C. Anthocyanin biosynthesis in apples stored at 14 or $25 \mathrm{C}$ showed an increase for the first day in the dark, after which no significant change was noted. These results indicate that cool temperatures are needed to enhance the development of red color development in UV-treated Royal Gala apple skin.

To further examine the development of red pigmentation in the cold, Royal Gala apples were irradiated for 1,2 , or 3 days at $14 \mathrm{C}$ and then stored for an extended period in the dark at 4C. Skin color was measured before and after UV irradiation (Table 1, B and A respectively) and after 15 (D 15) and 70 days (D 70) of storage in the dark at $4 \mathrm{C}$. The results from these experiments showed that following UV and white light irradiation for 2 days, maximum apple skin color was obtained after 15 days of storage in the dark. Longer storage periods did not further increase the pigmentation of Royal Gala apple skin. Marginal red pigmentation in apple skin occurred following a 3-day exposure to white light alone following storage in the dark for 15 days. Thus, red pigmentation in Royal Gala apple skin can be generated effectively using a combination of UV and white light ( 2 days) and cold storage at $4 \mathrm{C}$, since these two conditions seem to have a synergistic effect on the biosynthesis and accumulation of anthocyanins in Royal Gala apple skin. These results also demonstrate clearly that the UV enhanced red pigmentation of the Royal Gala apple skin is stable over prolonged periods of cold storage.

Induction of PAL and CHI enzymatic activity. Phenylalanine ammonia lyase (PAL) and chalcone isomerase (CHI) activities were measured in apple skin extracts after exposure to UV and white light irradiation for $0,8,16,24,48$, and 72 h. Figure 4 shows that PAL enzymatic activity in Royal Gala apple skin increased in a near linear fashion over the 3-day irradiation period. Activity in nonirradiated fruit was extremely low but it increased $\approx 30$-fold (from 0.025 to $0.78 \mathrm{pkat} / \mu \mathrm{g}$ protein) after irradiation for 3 days. These results show that the increase in enzymatic activity preceded the changes in anthocyanin concentrations (Fig. 1). Similar observations have been described by Faragher and Chalmers (1977) 
using Jonathan apples, except that the decline of PAL activity they reported was not observed here. The reason for this is that in their experiments the UV treatment was only for 15 rein, while under our experimental conditions the activity of PAL was measured during a 3-day continuous UV + white light irradiation period. Thus, Faragher and Chalmers (1977) observed a transient PAL enzymatic activity following a $15 \mathrm{~min}$ exposure to UV light. In Royal Gala PAL enzymatic activity also decreased following storage in the dark (unpublished data).

CHI enzymatic activity (Fig. 4) rapidly increased following irradiation treatment. It reached a maximum after 1 day and then, unlike PAL, stayed constant during the next 2 days of irradiation. Thus, the initial enzymatic response to UV irradiation was similar for PAL and CHI, but only PAL activity continued to increase further during the 72-h irradiation treatment. The nature of the difference in enzymatic activity between the two enzymes is subject to further investigation. These data suggest that the irradiation of intact green Royal Gala apples stimulates the enzyme activities of PAL and $\mathrm{CHI}$ in a coordinate manner. This increase in enzymatic activity is probably related to the induction of the PAL and CHI genes in Royal Gala apple skin. The coordinate expression of several structural genes in the phenylpropanoid and flavonoid pathways has been well documented in other plant systems (Goodrich et al., 1992; Jackson et al., 1992; Kubasek et al., 1992; Martin et al., 1991; Ohl et al., 1989; Tonelli et al., 1991; van Tunen et al., 1990).

PAL gene expression. To establish whether the increase in PAL enzymatic activity was a consequence of de novo biosynthesis, we determined the relative level of the PAL gene activity in apple skin by estimating the amount of PAL mRNA. Royal Gala apple skin was irradiated for $\mathrm{O}, 16$, and $32 \mathrm{~h}$ and total RNA was extracted from apple skin tissue as described by Mitra and Kootstra (1993). Total RNA was subjected to Northern analysis using a PAL probe. The autoradiogram (Fig. 5) shows that with increasing exposure to UV plus white light, the amounts of PAL mRNA increased relative to the ribosomal RNA signals. In the control apple the presence of PAL mRNA was detectable only as a faint band with longer exposure. In similar experiments we have also detected an increase in CHI mRNA synthesis during the irradiation of Royal Gala apple skin (unpublished data). These experiments provide evidence that following irradiation of Royal Gala apples flavonoid biosynthesis is induced in the apple skin and that the increased enzymatic activity of PAL (and CHI) is probably a consequence of induction at the level of transcription.

Summary. Analysis of the induction of anthocyanin biosynthesis in Royal Gala apple skin has demonstrated that the flavonoid pathway can be stimulated by white light. The addition of UV light significantly increased the formation and accumulation of anthocyanins in Royal Gala apple skin in a dose dependent manner. Storage of irradiated apples at $4 \mathrm{C}$ in the dark further increased the red apple skin color. Quantification of the flavonoids in UVinduced and naturally colored red apple skin showed that the relative distributions of flavonols, proanthocyanins and anthocyanins were similar, demonstrating that UV irradiation treatment produced naturally occuring flavonoid molecules. The enzymatic activity of both phenylalanine ammonia lyase, the first committed enzyme in the phenylpropanoid pathway, and chalcone isomerase were increased as a consequence of gene activation. Thus, the UVstimulated increase in apple skin pigmentation is accompanied by de novo synthesis of key enzymes in the phenylpropanoid and flavonoid pathways.

\section{Literature Cited}

Arakawa, O., Y. Hori, and R. Ogata. 1985. Relative effectiveness and interaction of ultraviolet-B, red and blue light in anthocyanin synthesis of apple fruit. Physiol. Plant. 64:323-327.

Arakawa, O. 1988, Photoregulation of anthocyanin synthesis in apple fruit under UV-B and red light. Plant Cell Physiol. 29:1385-1389.

Arakawa, O. 1991. Effect of temperature on anthocyanin accumulation in apple fruit as affected by cultivar, stage of fruit ripening and bagging. J. Hort. Sci. 66:763-768.

Asen, S., K.H. Norns, and R.N. Stewart. 1971. Effect of pH and concentration of the anthocyanin-flavonol co-pigment complex on the color of 'Better Times' roses. J. Amer. Soc. Hort. Sci. 96:770-773.

Avilla, J., C. Nieto, L. Canas, J. Benito and J. Paz-Ares. 1993. Petunia hybrids genes related to the maize regulatory $\mathrm{Cl}$ gene and to animal $m y b$ proto-oncogenes. Plant J. 3(4):553-562.

Bradford, M.M. 1976. A rapid and sensitive method for the quantitation of microgram quantities of proteins utilizing the principle of protein-dye binding. Anal. Biochem. 72:248-259.

Coe, E. H., M.G. Neuffer, and D.A. Hoisington. 1988. The genetics of corn, p. 8 1-258. In: G.F. Sprague and J.W. Dudley (eds.). Corn and improvements. Amer. Soc. Agron., Madison, Wis.

Consonni, G., F. Geuna, G. Gavzzi, and C. Tonelli. 1993. Molecular homology among members of the $R$ gene family in maize. Plant $\mathrm{J}$. 3(2):335-346.

De Warning, P., A.G.M. Gerats, H. Wiering, and H.J.W. Wijsman. 1984. Petunia hybrids: A short description of the activity of 91 genes, their origin and map location. Plant Mol. Biol. Rpt. 2:2-21.

Dooner, H.K. 1983. Co-ordinate genetic regulation of flavonoid biosynthetic enzymes in maize. Mol. Gen. Genet. 189:136-141.

Faragher, J.D. and D.J. Chalmers. 1977. Regulation of anthocyanin synthesis in apple skin. HI. Involvement of phenylalanine ammonialyase. Austral. J. Plant Physiol. 4:133-141.

Feinbaum, R.L. and F.M. Ausubel. 1988. Transcriptional regulation of the Arabidopsis thaliana chalcone synthase gene. Mol. Cell Biol. 8:19851992.

Forkmann, G. 1991. Flavonoids as flower pigments: The formation of the natural spectrum and its extension by genetic engineering. Plant Breeding 106:1-26.

Goodrich, J., R. Carpenter, and E.S. Coen. 1992. A common gene regulates pigmentation pattern in diverse plant species. Cell 68:955-964.

Harborne, J.B. 1988. Flavonoid checklist. In: J.B. Harborne (cd.). The flavonoids. Chapman and Hall, London.

Hrazdina, G. and G.J. Wagner. 1985. Compartmentation of plant phenolic compounds; sites of synthesis and accumulation, p. 119-1 33. In: C.F. Van Sumere and P.J. Lea (eds.). Annu. Proc. Phytochem. Soc. Europe. AVI, Westport, Corm.

Jackson, D., K. Roberts, and C. Martin. 1992. Temporal and spatial control of gene expression of anthocyanin biosynthetic genes in developing flowers of Antirrhinum majus. Plant J. 2(4):425-434.

Kubasek, W. L., B.W. Shirley, A. McKillop, H.M. Goodman, W. Briggs, and F.M. Ausubel. 1992. Regulation of flavonoid biosynthetic genes in germinating Arabidopsis seedlings. Plant Cell. 4:1229-1236.

Kuhn, D. N., J. Chappell, A. Boudet and K. Halbrock. 1984. Induction of phenylalanine ammonia lyase and coumaroyl CoA ligase mRNA in cultured plant cells by UV light or fungal elicitor. Proc. Natl. Acad. Sci. (USA) 81:1102-1106.

Lamb, C.J., M.A. Lawton, M. Dron, and R.A. Dixon. 1989. Signals and transduction mechanisms for activation of plant defence against microbial attack. Cell 56:215-218

Lancaster, J.E. 1992, Regulation of skin color in apples. Crit. Rev. Plant Sci. 10:487-502.

Lancaster, J. E., J. E. Grant, C. E. Lister, and M.C. Taylor. 1994. Skin color in apples- Influence of Copigmentation and Plastid Pigments on Shade and Darkness of Red Color in Five Genotypes. J. Amer. Soc. Hort. Sci. 119: $63-69$. 
Lister, C.E., J.E. Lancaster, K.H. Sutton, and J.R.L. Walker. Developmental changes in the concentration and composition of flavonoids in skin of a red and green apple cultivar. J. Sci. Food Agr. (In press.)

Ludwig, S. R., L.F. Habera, S.L. Dellaporta, and S.R. Wessler. 1989. Lc, a member of the maize $R$ gene family responsible for tissue-specific anthocyanin production, encodes a protein similar to transcriptional activators and contains the myc- homology region. Proc. Natl. Acad.Sci. (USA) 86:7092-7096

Martin, C., A. Prescott, S. Mackay, J. Bartlett, and E. Vtijlandt. 1991. The control of anthocyanin biosynthesis in flowers of Antirrhinum majus. Plant J. 1:37-49.

Mazza, G. and R. Brouillard. 1990. The mechanism of co-pigmentation of anthocyanins in aqueous solutions. Photochemistry 29: 1097-1 102.

McGuire, R.G. 1992. Reporting of objective color measurements. HortScience 27:1254-1255.

Mitra, D. and A. Kootstra. 1993. Isolation of RNA from apple skin. Plant Mol. Biol. Rpt. 11:326-332.

Mel, J.N.M., M.P. Robbins, R.A. Dixon, and E. Veltkamp. 1985. Spontaneous and enzymatic rearrangement of naringenin chalcone to flavone. Photochemistry 24(10):2267-2269.

Mustafa. E. and E. Wong. 1967. Purification and properties of chalcone flavone isomerase from soya bean seed. Photochemistry 6:625-632.

Ohl, S., K. Halbrock, and E. Schafer. 1989. A stable blue light derived signal modulates ultra violet light induced activation of chalcone synthase gene in parsley cells. Planta 177:228-236.
Rabino, I. and A.L. Mancinelli. 1986. Light, temperature, and anthocyanin production. Plant Physiol. 81:922-924.

Roth, B.A., S.A. Goff, T.M. Klein, and M.E. Fromm. 1991. $C 1-$ and $R$ dependent expression of the Mais $B z l$ gene requires sequences with homology to mammalian myb and myc binding sites. Plant Cell 3:317325 .

Sambrook, J., E.F. Fritsch, and T. Maniatis. 1989. Molecular cloning: A laboratory manual. Cold Spring Harbor Laboratory, Cold Spring Harbor, N.Y.

Saure, M.C. 1990. External control of anthocyanin formation in apple. Scientia Hort. 42:181-218.

Tonelli, C., G. Consonni, S. F. Dolfini, S.L. Dellaporta, A. Viotti, and G. Gavazzi. 1991. Genetic and molecular analysis of $S n$, a light-inducible, tissue specific regulatory gene in maize. Mol. Gen. Genet. 225:401-410.

Van der Meer, I.M., A.R. Stuitje, and J.N.M. Mol. 1993. Regulation of general phenylpropanoid and flavonoid gene expression, p 125-155. In: D.P.S. Verma (cd.). Control of gene expression. CRC Press, Boca Raton, Fla.

Van Tunen, A.J., A.G.M. Gerats, and J.N.M. Mol. 1990. Flavonoid gene expression follows the changes in tissue development of two Petunia hybrida homeotic flower mutants. Plant Mol. Biol. Rpt. 8(1):50-60.

Voss D.H. 1992. Relating calorimeter measurement of plant color to the Royal Horticultural Society Colour Chart. HortScience 27:1256-1260.

Weely, S.V., A. Bleumer, R. Spruyt, and A.W. Schram. 1983. Chalcone isomerase in flowers of mutants of Petunia hybrida. Planta 159:226 